http://journal.unj.ac.id/unj/index.php/jpud

Volume 12 Edisi 2 November 2018

JURNAL PENDIDIKAN USIA DINI

DOI: https://doi.org/10.21009/JPUD.122

DOI: https://doi.org/10.21009/JPUD.122.19

\title{
IMPLEMENTASI KURIKULUM 2013 PENDIDIKAN ANAK USIA DINI (PAUD) DI SUMATERA SELATAN
}

\author{
Yetty Rahelly \\ Program Studi Pendidikan Anak Usia Dini, Universitas Sriwijaya \\ E-mail: yettyrahelly@gmail.com
}

\begin{abstract}
ABSTRAK
This research aims to find out the implementation of 2013 Curriculum for Early Childhood Education (ECE) in South Sumatra by using descriptive and qualitative methods. Data was collected by using interview, questionnaire, observation, and documentation. The data was analyzed by using triangulation technique through reduction, display, and verification. The result showed that the implementation of 2013 Curriculum for Early Childhood Education (ECE) began with the preparation of semester Planning learning tools (PROMES), Weekly Learning Plans (WLP), Daily Learning Implementation Plans (DLP), and Assessment Plans. The process of implementing learning with a scientific approach is done when stepping up before playing, playing activities, and communicating stages. Principals and teachers worked together in designing learning devices. Then, they discussed about themes, sub-themes and game ideas that are able to develop aspects of development in an integrated manner based on scientific approach. The assessments were carried out with authentic assessments such as observation, portfolio, performance and assignments. Before the learning process, the teachers were required to prepare daily lesson plans and learning media which will be used later in the learning process.
\end{abstract}

\section{Keywords: Early Childhood Education, 2013 Curriculum Implementation}

Penelitian ini bertujuan untuk mengetahui bagaimana implementasi Kurikulum 2013 PAUD di Sumatera Selatan dengan menggunakan metode deskriptif-kualitatif. Pengumpulan data dilakukan dengan wawancara, angket, observasi serta dokumentasi. Analisis data digunakan dengan teknik triangulasi melewati beberapa proses yakni reduksi data, penyajian data, dan penarikan kesimpulan/ verifikasi. Hasil penelitian menunjukkan implementasi kurikulum 2013 PAUD diawali dengan penyusunan perangkat pembelajaran Perencanaan Semester (PROMES), Rencana Pelaksanaan Pembelajaran Mingguan (RPPM), Rencana Pelaksanaan Pembelajaran Harian (RPPH), dan Perencanaan Penilaian. Proses pelaksanaan pembelajaran dengan pendekatan saintifik dilakukan saat pijakan sebelum main, kegiatan main, dan tahap mengkomunikasikan. Kepala Sekolah dan guru ikut bekerja sama dalam merancang perangkat pembelajaran. Kemudian, mereka mengkomunikasikan tema, subtema dan ide permainan yang mampu mengembangkan aspek perkembangan secara terpadu berbasis pendekatan saintifik. Penilaian yang dilakukan berupa penilaian otentik, misalnya observasi, portofolio, unjuk kerja dan penugasan. Sebelum proses pembelajaran guru juga diwajibkan untuk mempersiapkan RPP harian dan media pembelajaran yang nanti akan digunakan dalam proses pembelajaran.

Kata Kunci : Implementasi Kurikulum 2013, Pendidikan Anak Usia Dini (PAUD) 


\section{PENDAHULUAN}

Anak merupakan makhluk individu generasi penerus bangsa yang memiliki karakter yang unik. Perkembangan yang fundamental terjadi saat usia dini dikenal dengan Periode Emas (The Golden Age). Pembentukan kecerdasan pada otak terjadi sejak janin hingga usia 6 tahun mencapai sekitar $80 \%$. Sedangkan $20 \%$ terjadi sejak usia 6 tahun keatas hingga masa tua.

Pemerintah melakukan upaya pembinaan untuk mengembangkan potensi yang dimiliki anak, hal ini selaras dengan Undang-undang Nomor 20 tahun 2003 tentang Sistem Pendidikan Nasional, Bab 1, pasal 1, butir 14 yang menyatakan bahwa: Pendidikan Anak Usia Dini adalah suatu upaya pembinaan yang ditujukan kepada anak sejak lahir sampai dengan usia 6 tahun yang dilakukan melalui pemberian rangsangan Pendidikan untuk membantu pertumbuhan dan perkembangan jasmani dan rohani agar anak memiliki kesiapan dalam memasuki Pendidikan lebih lanjut.

Kurikulum mengalami proses pengembangan penyempurnaan guna meningkatan kualitas Pendidikan Indonesia. Kurikulum 2013 Pendidikan Anak Usia Dini merupakan bagian dari pengembangan penyempurnaan kurikulum baru. Kurikulum 2013 dirancang berbasis kompetensi dan karakter. proses pembelajaran kurikulum $2013 \quad$ PAUD menggunakan pendekatan saintifik dan penialain otentik. Pendekatan saintifik dalam proses pembelajaran guna dapat membangun kebebasan imajinasi, berpikir kritis, dan kreativitas anak. Lalu, penilaian otentik bertujuan untuk mengukur tingkat perkembangan anak dalam proses pembelajaran.

Guru merupakan faktor penting dalam implementasi kurikulum. Pengamatan dilapangan ditemukan guru masih belum memahami penyusunan rancangan pembelajaran yang telah ditetapkan standar kurikulum. Akibatnya, pembelajaran tidak berjalan sesuai yang diharapkan. Pendekatan saintifik tidak terjadi pada proses pembelajaran. Latar belakang Pendidikan guru di sekolah sebagian besar bukan dari lulusan sarjana PAUD sehingga belum memahami penilaian otentik secara baik.

Berdasarkan wawancara bersama guru terungkap bahwa sebelum implementasi kurikulum PAUD 2013 Kepala Sekolah dan pendidik diberikan pelatihan terlebih dahulu guna kesiapan Lembaga PAUD melaksanakan perubahan kurikulum. Akan tetapi, DIKNAS didaerah setempat kurang mensosialisasikan Kurikulum 2013 ke sekolah. Berangkat dari beberapa faktor yang di atas, maka penulis berinisiatif untuk meneliti bagaimana implementasi Kurikulum 2013 PAUD di Sumatera Selatan. 


\section{KAJIAN TEORITIK}

Komponen pendidikan yang paling dasar untuk menentukan keberhasilan dalam menghasilkan sumber manusia yang dikehendaki suatu negara adalah kurikulum. Olivia (1992) mengungkapkan tentang kurikulum sebagai berikut:

“... Curriculum is perceived as a plan or program for all the experiences which the learner encounters under the direction of the school. In Practice, the curriculum consists of a number of plans, in written from and of varying scope, that delineate the desired learning experiences. The curriculum, therefore, may be a unit, a course, a sequence of course, the school's entire program of studies and may take place outside of class or school when directed by the personnel of the school ".

Perencanaan

sebelum

melaksanakan pembelajaran dituangkan dalam kurikulum. Kurikulum secara konsep merupakan merupakan rencana kegiatan atau dokumen tertulis yang mencakup strategi untuk mencapai tujuan (Ornstein, 2004). Sehingga kurikulum dapat diartikan sebagai arencana-rencana yang akan dilaksanakan dalam pembelajaran dan dituliskan menjadi sebuah dokumen. Dokumen tersebut yang kemudian dinamakan kurikulum yang akan menjadi arahan pembelajaran di sebuah lembaga.

Pada dasarnya kurikulum merupakan pedoman rencana mengenai program pembelajaran secara menyeluruh yang berisikan semua pengalaman belajar, materi pembelajaran disesuaikan dengan tahapan perkembangan anak yang akan diberikan kepada anak melalui proses pembelajaran di dalam atau di luar sekolah masih berada di bawah pengawasan sekolah. Menurut Ayob et al., (2016) Kurikulum yang telah dirancang bertujuan memberikan pengajaran, pengasuhan dan pendidikan untuk membina keperibadian anak, serta perkembangan bidang-bidang lain. Agar mampu mengembangkan pengalaman dan menguasai keterampilan dasar yang diperlukan untuk mencapai ke tingkat pengetahuan dan kemampuan akuisi yang lebih tinggi. Untuk itu mereka akan lebih mampu untuk masuk ke jenjang sekolah berikutnya.

Proses pembelajaran dalam suatu lembaga akan terarah apabila mempunyai pedoman yang jelas. Pedoman untuk mengarahkan proses pelaksanaan pembelajaran tersebut dituangkan dalam kurikulum. Guru sebagai pelaksana pembelajaran harus memahami konsep kurikulum. Karena konsep kurikulum yang dipahami oleh guru akan mempengaruhi proses pembelajaran. Komponen penting dalam pelaksanaan suatu pembalajaran yaitu kurikulum. Kurikulum pembelajaran sebagai elemen penting dalam pelaksanaan pembelajaran memegang peran penting dalam memberikan 
arah, langkah-langkah dan tujuan pelaksanaan pendidikan (Cholimah, 2012). Oleh karenanya kurikulum mutlak dibutuhkan untuk berlangsungnya suatu proses pembelajaran yang baik. Kurikulum dan pembelajaran merupakan suatu paket yang saling berkaitan satu sama salin. Kurikulum yang merupakan perencanaan tidak bermakna apabila tidak dilaksanakan dalam proses pembelajaran. Pembelajaran tidak dapat dilaksanakan dengan baik tanpa ada panduan kurikulum. "Without a curriculum or plan, there can be no effective instruction and without instruction the curriculum has little meaning" (Saylor \& Alexander, 1981).

Proses dalam membuat suatu kurikulum terdapat 6 langkah, yaitu rekabentuk, membina, melaksana, memantau, menilai dan mereview. Setelah proses ini dijalankan, maka barulah suatu kurikulum itu boleh diimplementasikan secara menyeluruh (Brady, 1995). Teori Pendidikan progresif aliran Jhon Dewey memiliki pengaruh yang kuat dalam kurikulum 2013 PAUD. Hal ini terlihat dari Child centered sebagai kebijakan pola pembelajaran. Dewey dalam Morrison (2012) menyakini bahwa kurikulum perlu dibuat dengan menekankan minat anak dan difokuskan pada penyelesaian masalah anak sehari-hari.

$$
\text { Kurikulum } 2013 \text { PAUD }
$$

berorientasi pada pendekatan saintifik. Penyusunan isi kurikulum bersifat unified atau concentrated curriculum. Unified atau concerntrated curriculum adalah pola penyusunan bahan pembelajaran yang tersusun dari tema-tema pembelajaran dan didalam tema tersebut mencakup materi berbagai bahan disiplin ilmu (Prihatini, 2014). Oleh sebab itu, Kurikulum 2013 PAUD berbasis tematik pembelajaran. Metode yang pembelajaran yang diterapkan melalui cooperative learning, sosiodrama, kerja lapangan, kerja kelompok. Pelaksanaan kegiatan pembelajaran dilakukan secara bermain. Sasaran evaluasi ialah perkembangan anak untuk menjadi makhluk yang mandiri. Evaluasi yang ditekankan yakni proses daripada hasil.

Kurikulum 2013 juga dirancang untuk menyiapkan siswa ke jenjang pendidikan selanjutnya. Atau dengan kata lain, kurikulum 2013 PAUD disusun untuk membelakali siswa agar memilki kesiapan sekolah dari berbagai aspek pekembangan. Karena faktor kesiapan sekolah seorang anak yang dituangkan dalam kurikulum mencakup semua aspek. Meskipun pada kenyataannya kesiapan sekolah umumnya hanya dilihat dari kemampuan membaca, menulis dan berhitung. Kesiapan untuk memasuki sekolah dasar lebih menitikberatkan pada aspek koginitif dan literasi seperti membaca, menulis, dan berhitung (Syarfina, Yetti, \& Fridani, 2018). 
Implementasi Kurikulum 2013

Yetty Rahelly

Prinsip konsep belajar dan lingkungan belajar dipersiapkan secara keterpaduan dan bersifat holistik. Konsep kurikulum 2013 PAUD yang tercantum dalam Lampiran 1 Permendikbud Nomor 146 Tahun 2014 sebagai berikut: (1) Mengoptimalkan perkembangan anak yang meliputi berbagai aspek perkembangan yakni nilai agama dan moral, fisik-motorik, kognitif, bahasa, Sosial emosional, dan seni yang tercermin dalam keseimbangan kompetensi sikap, pengetahuan, dan keterampilan; (2) Pembelajaran menggunakan pendekatan berbasis saintifik; (3) Penilaian untuk mengukur perkembangan anak menggunakan penilaian autentik; dan (4) memberdayakan peran orang tua dalam proses pembelajaran (Permendikbud, 2014).

Kurikulum yang baik merupakan kurikulum yang menyesuaikan kebutuhan masing-masing daerah. Hal ini sebagaimana yang disampaikan oleh Gestwicki bahwa kurikulum sebaiknya juga menyesuaikan dengan kebutuhan daerah dan perkembangan jaman agar kebermanfaatannya dapat dicapai (Getstwicki, 2007). Hal ini dapat dipahami bahwa penyesuian kurikulum berdasarkan kebutuhan daerah bertujuan agar keberadaan kurikulum dapat dirasakan manfaatnya oleh siswa. Kurikulum bukan hanya sekedar dokumen sebuah lembaga namun juga sebagai arahan untuk peningkatan kompetansi siswa khususnya terkait dengan potensi lokal daerah. Misalnya wilayah pesisir, kurikulumnya dirancang sesuai dengan kebutuhan pesisir dan sebagainya. Sehingga diharapkan implementasi kurikulum dapat bermakna bagi siswa.

Target kompetensi yang telah ditetapkan dalam Kurikulum PAUD 2013 tercantum di Lampiran 1 Permendikbud Nomor 146 Tahun 2014. Kompetensi standar yang perlu dicapai oleh anak yakni Kompetensi Inti (KI) dan Kompetensi Dasar (KD). Kompetensi inti merupakan deskripsi Standar Tingkat Pencapaian Perkembangan Anak (STPPA) sejak usia lahir hingga usia 6 tahun. Mencakup aspek sikap spiritual, sosial, pengetahuan, dan keterampilan. Sedangkan, Kompetensi Dasar merupakan Tingkat Kemampuan dalam konteks pembelajaran, tema pembelajaran, dan pengalaman belajar anak yang mengacu pada Kompetensi Inti. Rumusan Kompetensi Dasar dikembangan dengan memperhatikan karakteristik dan kemampuan awal anak serta tujuan setiap program pengembangan.

\section{METODE PENELITIAN}

Penelitian ini menggunakan metode deskriptif kualitatif. Lokasi tempat penelitian Sumatera Selatan dengan tiga TK untuk objek penelitian, yakni TK Rosa Palembang, TK Antarsita Bukit Asam, dan TK Mutiara Bangsa Lubuk 
Linggau. Teknik pengumpulan data dilakukan dengan wawancara, observasi dan juga dokumentasi. Sumber data diperoleh dari Kepala sekolah, dan guru. Analisis data di lapangan Model Miles dan Huberman. Menurut Sugiyono (2012), terdapat tiga aktivitas analisis data Model Miles dan Huberman yakni reduksi data (data reduction), penyajian data (data display), dan penarikan kesimpulan (conclusion drawing or verification). Kemudian, keabsahan data diuji melalui:
Triangulasi, Kreadibilitas

(credibility), Transferabilitas

(transferability), dan

Komfirmabilitas (confirmability).

\section{HASIL DAN PEMBAHASAN}

Implementasi Kurikulum Pendidikan Anak Usia Dini (PAUD) 2013. Terdapat variasi implementasi kurikulum pada tiap-tiap sekolah. Adapun implementasi kurikulum PAUD 2013 di 3 Tk Sumatera Selatan dijelaskan pada tabel sebagai berikut:

Tabel 2. Implementasi Kurikulum Pendidikan Anak Usia Dini 2013

\begin{tabular}{|c|c|c|c|}
\hline $\begin{array}{c}\text { Nama } \\
\text { TK }\end{array}$ & $\begin{array}{c}\text { Implementasi } \\
\text { Kurikulum PAUD } \\
2013\end{array}$ & $\begin{array}{c}\text { Kendala } \\
\text { Implementasi } \\
\text { Kurikulum PAUD } \\
2013\end{array}$ & $\begin{array}{c}\text { Solusi Implementasi } \\
\text { Kurikulum PAUD } 2013\end{array}$ \\
\hline TK R & $\begin{array}{l}\text { Kebijakan Kepala } \\
\text { Sekolah dalam } \\
\text { menyusun perangkat } \\
\text { pembelajaran } \\
\text { sebelum } \\
\text { pembelajaran } \\
\text { melibatkan guru- } \\
\text { guru yang ada di } \\
\text { sekolah untuk ikut } \\
\text { bekerjasama. } \\
\text { Perangkat } \\
\text { pembelajaran yang } \\
\text { telah dibuat oleh guru } \\
\text { harapannya dapat } \\
\text { dijadikan sebagai } \\
\text { pedoman dalam } \\
\text { proses pelaksanaan } \\
\text { pembelajaran yang } \\
\text { mengarah pada } \\
\text { pendekatan saintifik. } \\
\text { Teknik penilaian } \\
\text { berupa penilaian } \\
\text { autentik misalnya }\end{array}$ & $\begin{array}{l}\text { Format perencanaan } \\
\text { (Prosem, RPPM, } \\
\text { RPPH, dan } \\
\text { Penilaian) yang rumit } \\
\text { bagi guru. } \\
\text { Pendekatan saintifik } \\
\text { tidak } \\
\text { mengembangkan } \\
\text { aspek perkembangan } \\
\text { secarra terpadu dan } \\
\text { proses saintifik tidak } \\
\text { terekam selama } \\
\text { bermain. }\end{array}$ & $\begin{array}{l}\text { Diadakannya pertemuan } \\
\text { yang berhubungan dengan } \\
\text { pembuatan perangkat } \\
\text { pembelajaran } \\
\text { membahas mengenai ide } \\
\text { main yang mampu } \\
\text { memgembangkan aspek } \\
\text { perkembangan anak secara } \\
\text { terpadu. Jika masih } \\
\text { terdapat masalah guru } \\
\text { menyampaikan kepada } \\
\text { kepala sekolah untuk } \\
\text { mencari solusi bersama- } \\
\text { sama. Apabila kepala } \\
\text { sekolah tidak menemukan } \\
\text { solusi akan menghubungi } \\
\text { pengawas sekolah selain } \\
\text { itu guru juga bisa sharing } \\
\text { dengan sesama guru } \\
\text { pelaksana kurikulum } 2013 .\end{array}$ \\
\hline
\end{tabular}




\begin{tabular}{|c|c|c|c|}
\hline & $\begin{array}{l}\text { observasi, portofolio, } \\
\text { unjuk kerja dan } \\
\text { penugasan. }\end{array}$ & & \\
\hline TK A & $\begin{array}{l}\text { Diawali dengan } \\
\text { Penyusunan Program } \\
\text { semester, Rencana } \\
\text { pelaksanaan } \\
\text { pembelajaran } \\
\text { mingguan, Rencana } \\
\text { pelaksanaan } \\
\text { pembelajaran harian, } \\
\text { dan Perencanan } \\
\text { penilaian. Dalam } \\
\text { implementasi } \\
\text { pembelajaran guru } \\
\text { menggunakan alat } \\
\text { dan bahan yang } \\
\text { beragam. }\end{array}$ & $\begin{array}{lr}\text { Pola pembelajaran } \\
\text { berpusat } & \text { pada anak } \\
\text { sehingga } & \text { pendekatan } \\
\text { saintifik } & \text { muncul. } \\
\text { Proses penilaian } & \text { ptentik dilakukan } \\
\text { dengan penilaian } \\
\text { harian yang } \\
\text { menggunakan } \\
\text { Teknik pengumpulan } \\
\text { data, kompilasi data } \\
\text { mingguan, kompilasi } \\
\text { data bulanan dan } \\
\text { laporan } \\
\text { perkembangan anak. }\end{array}$ & $\begin{array}{lr}\text { Pendekatan } & \text { saintifik } \\
\text { membutuhan ide main } \\
\text { yang terpadu } \\
\text { meningkatkan aspek } \\
\text { perkembangan anak. TK A } \\
\text { telah melaksanakan catatan } \\
\text { anekdot, pengelolaan data, } \\
\text { kompilasi data mingguan, } \\
\text { kompilasi data bulanan } \\
\text { serta dalam penulisan } \\
\text { laporan perkembangan } \\
\text { anak. }\end{array}$ \\
\hline TK MB & $\begin{array}{lr}\text { Adanya pembinaan } \\
\text { dari dinas pendidikan } \\
\text { dan kebudayaan kota } \\
\text { Lubuk linggau. } \\
\text { Fasilitas rang } \\
\text { dimiliki berupa APE } \\
\text { yang menunjang } \\
\text { kegiatan } \\
\text { pembelajaran. }\end{array}$ & 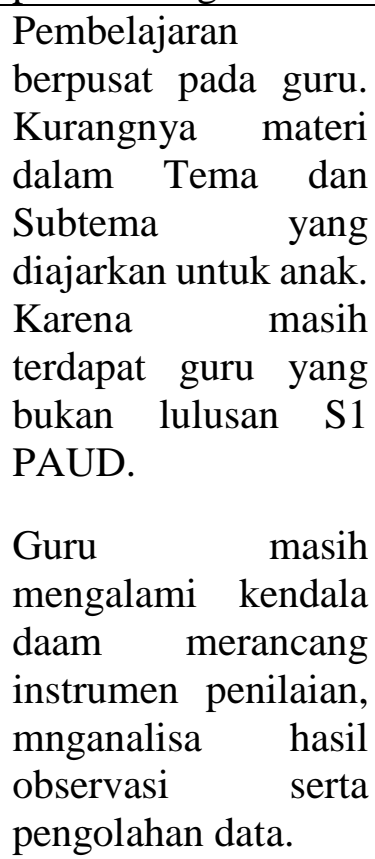 & $\begin{array}{l}\text { Perlu latihan untuk } \\
\text { memahami materi yang } \\
\text { akan disampaikan dalam } \\
\text { tema dan subtema. } \\
\text { Selanjutnyan merancang } \\
\text { kegiatan bermain yang } \\
\text { terpadu dan berlatih dalam } \\
\text { menganalisa hasil } \\
\text { observasi serta pengolahan } \\
\text { data. }\end{array}$ \\
\hline
\end{tabular}

Leksonso, Sulton and Susilaningsih, (2016) menyatakan bahwa kurikulum merupakan acuan pokok pelaksanaan pendidikan nasional. Kurikulum 2013 PAUD mencangkup semua dimensi tumbuh kembang anak (sikap, pengetahuan, dan keterampilan) dan mencangkup semua program pengembangan yang direncanakan dan disajikan secara terpadu dan berkesinambungan sesuai dengan tahap perkembangan anak.

Implementasi Kurikulum PAUD 2013 di Tiga Taman Kanak-Kanak 
(TK) yang menjadi tempat penelitian, diawali dengan penyusunan Program Semester (PROMES), Rencana Pelaksanaan Pembelajaran Mingguan (RPPM), Rencana Pelaksanaan Pembelajaran. Harian (RPPH), dan Perencanaan Penilaian. Proses pelaksanaan pembelajaran dengan pendekatan saintifik dilakukan saat pijakan sebelum main, kegiatan main, dan tahap mengkomunikasikan.

Keberhasilan implementasi kurikulum sangat bergantung pada guru. Kurikulum dapat diimplemantasikan dengan baik apabila guru mempunyai komitmen untuk melaksanakan kurikulum tesebut. Selain itu kompetensi dan kreativitas guru juga menentukan keberhasilan implementasi kurikulum khsuusnya dalam penuyusunan dokumen kurikulum. Guru yang berhasil melaksanakan kurikulum mampu memilih dan menciptakan suasana pembelajaran yang menggairahkan siswa, mampu memilih dan melaksanakan metode mengajar yang sesuai dengan kemampuan siswa, bahan pelajaran dan melibatkan siswa secara aktif. Selain itu, guru mampu memilih, menyusun, dan melaksanakan evaluasi, baik untuk mengevaluasi perkembangan atau hasil belajar siswa untuk menilai efisiensi pelaksanaannya itu sendiri (Winarso, 2017).

Salah satu yang menjadi permasalahan dalam implementasi Kurikulum 2013 pada level RA/TK adalah model pembelajaran saintifik dan penilaian autentik yang harus disusun dalam RPPH guru di TK (Mukhibat, Fitri, \& Hartati, 2018). Oleh karena itu, pendekatan saintifik dinilai mampu mengembangan aspek perkembangan yang dimiliki anak secara terpadu. Mahmudah (2016) menyatakan bahwa pentingnya pemahaman tema dan subtema serta penguasaan materi ajar. Bila guru telah memahami konsep yang akan diajarkan maka pendekatan saintifik akan muncul dan kegiatan berpusat pada anak. Kurikulum PAUD 2013 menekankan penilaian otentik. otentik dilakukan berdasarkan berdasarkan analisa perkembangan secara keseluruhan, responsif dan berpusat pada anak.

\begin{tabular}{lrr}
\multicolumn{1}{c}{ Pada } & hakikatnya kurikulum \\
merupakan & pedoman yang \\
mengarahkan & pembelajaran.
\end{tabular}

Kurikulum adalah rencana program pendidikan. Oleh karena itu, perlu dipertimbangkan berbagai aspek dan faktor penentu keberhasilan implementasi kurikulum. Dalam hal ini kontrol dari masyarakat juga sangat dibutuhkan sehingga kurikulum dapat berjalan sesuai dengan yang sudah dirancang oleh tim perumus kurikulum itu sendiri. Dengan maksud mewadahi dan memaksimalkan peran serta masyarakat dalam penyelenggaraan pendidikan maka disinilah peran sebagai supporting agence menjadi sangat menentukan (Winarso, 2017). 
Implementasi Kurikulum 2013.

Yetty Rahelly

Kurikulum disusun sebagai pedoman pelaksanaan pembelajaran yang memiliki peranan penting pada seuatu lembaga pendidikan tak terkecuali lembaga pendidikan anak usia dini. Kurikulum merupakan standar minimal yang dapat dikembangkan ataupun dikurangi sesuai kebutuhan. Namun jika kurikulum sudah tidak sesuai dengan keadaan budaya, peserta didik, perkembangan jaman, dan masyarakat pengguna, satuan pendidik dapat mengembangkannya sesuai kebutuhan (Maryatun, 2014). Kurikulum dalam implementasinya dapat disesuaikan dengan keadaan budaya dan disesuaikan relevansinya dengan kehidupan sehari-hari.

\section{KESIMPULAN}

Hasil penelitian beberapa TK di Sumatera Selatan, yaitu TK Rosa Palembang, TK Antrasita Muara Enim, TK Mutiara Bangsa Lubuk Linggau, didapatkan kesimpulan yang signifikan implementasi kurikulum di 3 Taman Kanak-Kanak (TK) diawali dengan penyusunan perangkat pembelajaran Program Semester (PROMES), Rencana Pelaksanaan Pembelajaran Mingguan (RPPM), Rencana Pelaksanaan Pembelajaran Harian (RPPH), dan Perencanaan Penilaian. Proses pelaksanaan pembelajaran dengan pendekatan saintifik dilakukan saat pijakan sebelum main, kegiatan main, dan tahap mengkomunikasikan. Kepala Sekolah dan guru ikut bekerja sama merancang perangkat pembelajaran. Kemudian, mengkomunikasikan tema, subtema dan ide permainan yang mampu mengembangkan aspek perkembangan secara terpadu berbasis pendekatan otentik. Dan akan dilakukan penilaian dengan penilaian otentik misalnya observasi, portofolio, unjuk kerja dan penugasan.

Kesukaran guru dalam menyusun perangkat pembelajaran dikarenakan guru dengan latar belakang yang bukan pendidikan anak usia dini, kurangnya kompetensi yang dimiliki guru, dan informasi mengenai implementasi kurikulum PAUD 2013. Akan tetapi, kepala sekolah mengadakan workshop pelatihan. Apabila kepala sekolah tidak menemukan solusi akan menghubungi pengawas sekolah selain itu guru juga bisa sharing dengan sesama guru pelaksana kurikulum 2013. Dan sebelum proses pembelajaran juga guru diwajibkan untuk mempersiapkan RPP harian dan media pembelajaran yang nanti akan digunakan dalam proses pembelajaran.

\section{DAFTAR PUSTAKA}

Ayob, A., Badzis, M., Nordin, A. L., \& Abdullah, R. (2016). Kurikulum Permata Negara. Tanjong Malim: NCDRC, UPSI.

Brady, L. (1995). Curriculum development, 5th ed. Sydney: Prentice-Hall.

Cholimah, N. (2012). Pengembangan Kurikulum PAUD Berdasarkan 
Permen 58 Tahun 2009.

Getstwicki, C. (2007). Developmentally Appropriate Practice. Curriculum and Development In Early Education. Canada: Thomson Delmar Learning. Ornstein.

Leksonso, F. D. L., Sulton, S., \& Susilaningsih, S. (2016). Implementasu Kurikulum 2013 PAUD di TK TPI Nurul Huda Malang. JURNAL INOVASI DAN TEKNOLOGI PEMBELAJARAN, 126-131.

Mahmudah, D. (2016). Implementasi Kurikulum 2013 Pendidikan Anak Usia Dini dalam Pembelajaran. Universistas Islam Sunan Kalijaga, Yogyakarta.

Maryatun, I. B. (2014). Konsep Pengembangan Kurikulum PAUD.

Morrison, G. S. (2012). Dasar-dasar Pendidikan Anak Usia Dini. Jakarta: PT. Indeks.

Mukhibat, M., Fitri, N. F., \& Hartati, A. S. (2018). Pendampingan Implementasi Kurikulum 2013 untuk Peningkatan Mutu Pembelajaran Guru-guru (POKJA RA) Poncol di Magetan, 2(1).

Olivia, P. F. (1992). Developing the Curriculum (Third Edition). New York: Harper Collins Publishers Inc. Rosyada.

Ornstein,
A.
C.
(2004).

Curriculum:Foundation,

Principles, and Issues. Boston: Pearson Education, Inc.

Permendikbud, K. P. D. K. Permendikbud Nomor 146 Tahun 2014 KURIKULUM 2013 PENDIDIKAN ANAK USIA DINI (2014).

Prihatini, P. (2014). Kajian Ide Kurikulum 2012 PAUD dan Implikasinya dalam Pengembangan KTSP. Cakrawala Dini: Junal Pendidikan Anak Usia Dinia.

Saylor, J. G., \& Alexander, W. M. (1981). Curriculum Planning for Better Teaching and Learning.
Holt-Rinehart and Winston.

Sugiyono, S. (2012). Metode Penelitian Kuantitatif, Kualitatif, dan R\&D. Bandung: Alfabeta.

Syarfina, Yetti, E., \& Fridani, L. (2018).

Pemahaman Guru Prasekolah

Raudhatul Athfal Tentang Kesiapan

Sekolah Anak. Jurnal Pendidikan

Usia Dini, 12, 153-163. https://doi.org/https://doi.org/https: //doi.org/10.21009//JPUD.121.13

Winarso, W. (2017). Dasar Pengembangan Kurikulum Sekolah, (January 2015). 